\title{
Electrochemical Oxidation of Caffeic and Ferulic Acid Derivatives in Aprotic Medium
}

\author{
Magali Salas-Reyes, *,a Javier Hernández, ${ }^{a}$ Zaira Domínguez, ${ }^{a}$ Felipe J. González, ${ }^{b}$ \\ Pablo D. Astudillo, ${ }^{b}$ Rosa Elena Navarro, ${ }^{c}$ Evelin Martínez-Benavidez, ${ }^{d, a}$ \\ Carlos Velázquez-Contreras ${ }^{e}$ and Samuel Cruz-Sánchez ${ }^{a}$ \\ ${ }^{a}$ Unidad de Servicios de Apoyo en Resolución Analítica, Universidad Veracruzana, \\ Apdo. Postal 575, Xalapa, Ver., México \\ ${ }^{b}$ Departamento de Química del Centro de Investigación y Estudios Avanzados, Av. Instituto \\ Politécnico Nacional 2508, 07360, Apdo. Postal 14-740, México, D. F., México \\ 'Departamento de Investigación en Polímeros y Materiales, Hermosillo, Son., México \\ ${ }^{d}$ Instituto de Ciencias Básicas, Universidad Veracruzana, Apdo. Postal 525, Xalapa, Ver., México \\ ${ }^{e}$ Departamento de Ciencias Químico Biológicas, Universidad de Sonora, 83000, Hermosillo, Son., México
}

\begin{abstract}
O comportamento eletroquímico em função da estrutura de uma série de derivados dos ácidos cafeico e ferúlico, assim como de seus precursores catecol e guaiacol, eletroquimicamente ativos, foi avaliado por voltametria cíclica. Os resultados revelaram que as condições experimentais são a chave para as mudanças no mecanismo de oxidação do guaiacol e ácido ferúlico. A oxidação eletroquímica dos derivados amida do ácido ferúlico revelou que o átomo de nitrogênio desempenha um papel importante na derivatização da superfície do eletrodo. Além disso, a atividade sequestradora de radicais dos compostos, avaliada através da porcentagem de inibição do radical 2,2'-difenil-1picril-hidrazila, mostrou uma boa correlação com os potenciais de oxidação.
\end{abstract}

We studied the electrochemical behaviour as a function of the structure of a series of caffeic and ferulic acids derivatives as well as their corresponding redox moieties catechol and guaiacol by cyclic voltammetry. Results revealed that the medium is key for changes in the oxidation mechanism of guaiacol and ferulic acid. Electrochemical oxidation of the ferulic acid amide derivatives revealed that the nitrogen atom plays an important role in the derivatization of the electrode surface. In addition, radical scavenging activity of the compounds evaluated through the percentage of inhibition of the 2,2'-diphenyl-1-picrylhidrazyl radical showed a good relationship with the oxidation potentials.

Keywords: cyclic voltammetry, hydroxycinnamic acids, caffeic acid phenethyl ester, antioxidant activity, DPPH radical

\section{Introduction}

Caffeic (CA) and ferulic (FA) acids and their corresponding esters are widely distributed in plants and also in propolis from diverse geographic zones of the world. ${ }^{1,2}$ During the last years, these compounds have received the attention of numerous research groups since it has been suggested that some of them have important biological properties. ${ }^{3-18}$ Special interest has received caffeic acid phenethyl ester (CAPE), which is one of the most active components isolated from honeybee propolis.

*e-mail: magasalas@uv.mx
It has been demonstrated that CAPE is an efficient free radical scavenger and an inhibitor of some enzymes as cyclooxygenase, ${ }^{17}$ lipoxygenase, and the HIV-1 integrase.$^{5,18}$ Additionally, it possesses antiinflammatory and antitumor activities. ${ }^{14-16}$ Particularly, the antitumor activity of CAPE has been related to its capacity to induce apoptosis and also to modulate the cellular redox states. ${ }^{19,20}$

Since the biological activity of CA and FA is related to the electron transfer processes, several mechanistic studies on the electrochemical oxidation of these acids have been documented in the literature. ${ }^{21-25}$ However, to the best of our knowledge, no study has been focused to understand the electrochemical behavior of its corresponding esters 
or amides, nevertheless some compounds such as CAPE and caffeic acid phenethyl amide (CAPEA) have shown even higher in vitro antioxidant activity respect to that of CA. ${ }^{9,10,26}$

In the present work the anodic oxidation of a series of caffeic and ferulic acids derivatives (Figure 1) in aprotic medium is reported, as well as for their corresponding redox moieties catechol (C) and guaiacol (G). Some mechanistic details of the redox behavior of the complete series were investigated and are also discussed here, since they may be related to the known antioxidant properties of this kind of compounds in biological systems. The radical scavenging activity of the ten compounds was also evaluated using the DPPH assay, in order to analyze if there is a relationship between this property and the corresponding potential oxidation value.

\section{Experimental}

\section{Chemicals}

Tetrabutylammonium hexafluorophosphate $98 \%$ $\left(\mathrm{n}-\mathrm{Bu}_{4} \mathrm{NPF}_{6}\right)$, catechol $(\mathrm{C})(99 \%)$, guaiacol $(\mathrm{G})(>98 \%)$, ferulic acid (FA) (99\%), dihydrocaffeic acid (DHCA) (99\%), caffeic acid (CA) (99\%), and 2,2'-diphenyl-1picrylhidrazyl radical (DPPH) were purchased from Sigma-Aldrich. Acetonitrile (AN) (content of $\mathrm{H}_{2} \mathrm{O}<0.1 \%$ ), dimethylsulfoxide (DMSO) (content of $\mathrm{H}_{2} \mathrm{O}<0.1 \%$ ) spectra grade (Merck Uvasol) and ethanol chromasolv® were used as solvents. Caffeic acid phenethyl ester (CAPE) was prepared according to the procedure reported by Grunberger. ${ }^{27}$ All of the amides were synthesized from the free acid and the corresponding amine using (benzotriazol-1-yloxy)tris(dimethylamino)phosphonium hexafluorophosphate (BOP) as coupling reagent, as has been described before. ${ }^{9}$

\section{Free radical scavenging activity (DPPH assay)}

The free radical scavenging activity (FRS) was measured according to the following procedure: $500 \mu \mathrm{L}$ of a 2,2'-diphenyl-1-picrylhidrazyl radical (DPPH) ethanolic solution $\left(300 \mu \mathrm{mol} \mathrm{L}^{-1}\right)$ was mixed with the same

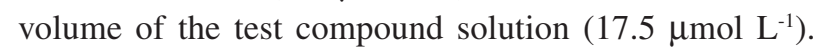
The reaction mixtures were vigorously vortexed for $10 \mathrm{~s}$. Absorbance of the resulting solutions was read at<smiles>Oc1ccccc1O</smiles>

c<smiles>COc1ccccc1O</smiles>

G<smiles>O=C(O)/C=C/c1ccc(O)c(O)c1</smiles>

CA<smiles>O=C(O)CCc1ccc(O)c(O)c1</smiles><smiles>COc1cc(/C=C/C(=O)O)ccc1O</smiles><smiles>O=C(/C=C/c1ccc(O)c(O)c1)OCCc1ccccc1</smiles><smiles>O=C(/C=C/c1ccc(O)c(O)c1)NCCc1ccccc1</smiles>

CAPEA<smiles>CC(C)(C)OC(C)(C)C</smiles><smiles>CCCCCNC(=O)C=Cc1ccc(O)c(OC)c1</smiles><smiles>CCCCC(C)CC(C)C</smiles>

Figure 1. Compounds studied in the present work. 
$517 \mathrm{~nm}$ in a spectrophotometer (Varian, CARY 100), after $30 \mathrm{~min}$ of incubation at room temperature in darkness. The scavenging activity was determined by comparing the absorbance with that of the blank containing only 2,2'-diphenyl-1-picrylhidrazyl radical (DPPH) and ethanol. Results were expressed as inhibition percentage. ${ }^{3}$

\section{Instrumentation and electrodes}

Cyclic voltammetry and coulometry experiments were performed in a radiometer potentiostat 1MT102-DEA332 with positive feedback resistance compensation. A threeelectrode cell was used in the electrochemical experiments. The working electrode was a $3 \mathrm{~mm}$ diameter glassy carbon disk (Sigradur G from HTW, Germany). This electrode was polished with $1 \mu \mathrm{m}$ alumina powder and rinsed in ultrasound bath with distilled water and ethanol before each run. Platinum mesh was used as counter electrode and saturated calomel electrode (SCE) as reference. The reference electrode was connected to the cell through a salt bridge containing the same supporting electrolyte concentration as the working solution. All electrochemical experiments were performed at $25{ }^{\circ} \mathrm{C}$ under an argon atmosphere. Coulometry was carried out with a glassy carbon rotating rod electrode under constant rotation $(1000 \mathrm{rpm})$ and controlled potential.

\section{Results and Discussion}

Electrochemical study of the oxidation process of $C, G, C A$, DHCA, CAPE and FA

The electrochemical behaviour in acetonitrile of caffeic acid (CA), dihydrocaffeic acid (DHCA), caffeic acid phenethyl ester (CAPE), guaiacol (G), and ferulic acid (FA) showed a typical chemically irreversible oxidation wave (I) and the corresponding broadened reduction wave (II) in the reverse scan. The voltammogram of CAPE is shown in Figure 2a as a representative example of this behaviour. The bielectronic nature of the oxidative process of CAPE was confirmed by coulometry $\left(\mathrm{n}_{\mathrm{app}}=2.02\right)$. Since the current peak intensity $\left(\mathrm{i}_{\mathrm{p}}\right)$ for the rest of the systems was similar to the current peak intensity recorded for CAPE at the same scan rate and concentration, it was deduced that the electron stoichiometry was also two in all the cases.

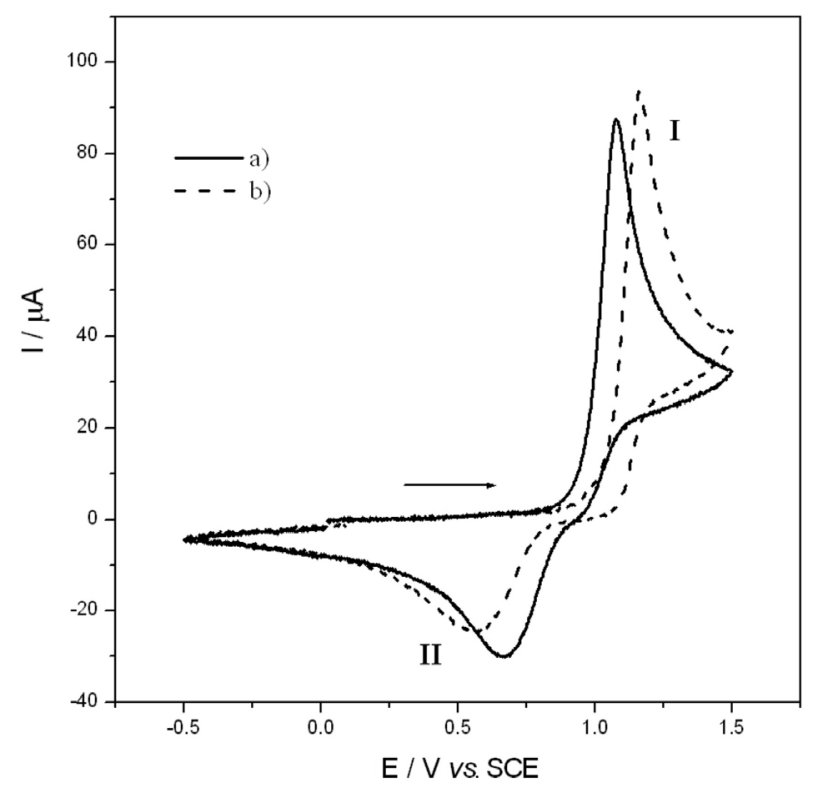

Figure 2. Cyclic voltammetry in acetonitrile $+0.2 \mathrm{~mol} \mathrm{~L}^{-1} n-\mathrm{Bu}_{4} \mathrm{NPF}_{6}$, on glassy carbon electrode $(3 \mathrm{~mm} \phi)$ at $2 \mathrm{mmol} \mathrm{L}^{-1}$ and $0.1 \mathrm{~V} \mathrm{~s}^{-1}$ of a) CAPE and b) FA.

The electrochemical responses of CA, DHCA, and CAPE under these experimental conditions are similar to that found for catechol, and are in good agreement with the anodic oxidation of hydroquinone (an isomer of catechol) reported before, ${ }^{28-32}$ which follows an ECE mechanism that involves the lost of one electron in the system, followed by a fast deprotonation reaction and, finally, the lost of a second electron. Scheme 1 shows the complete mechanism, which is the starting point for the following discussion. A further deprotonation reaction is also included as the last step, since additional spectroscopic studies have suggested that the $o$-quinone $(\mathrm{Q})$ is obtained as the final product. ${ }^{28}$

In Figure $2 b$, it can also be observed that the voltammogram of FA did not show significant differences with respect to the electrochemical responses of catechol and caffeic acid derivatives, such as CAPE (Figure 2a). Consequently, a two-electron mechanism is also involved in the oxidation of G and FA in acetonitrile. Despite the fact that the electrochemical oxidation of both compounds is still unclear, it is known that the mechanism involves the $o$-quinone form, which has been identified as the main product obtained during the oxidation of FA..$^{25,28}$

When the scan rate is increased in the case of CA, FA, and CAPE, the peak potential I is anodically shifted,

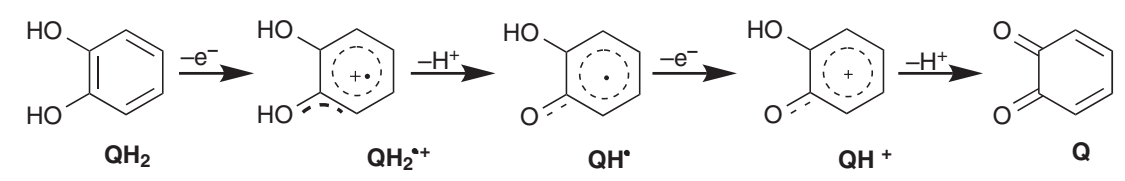

Scheme 1. 
showing a linear variation with the logarithm of the scan rate of 31,30 , and $42 \mathrm{mV} \mathrm{dec}^{-1}$, respectively (Table 1). The analysis of a transition of the mechanism controlled by the follow-up chemical reaction to a mechanism where the electron transfer is rate determining, has been well characterized. ${ }^{33}$ Thus, at $25^{\circ} \mathrm{C}$, this transition involves

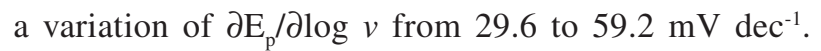
The results presented here suggest that in the case of CA and FA the initial electron and proton transfer reactions are consecutive, and they occur under a pure kinetic control of the radical cation deprotonation. In contrast, the substitution of the acidic proton of the caffeic acid by the phenethyl group induces an increase in the rate of the deprotonation chemical reaction in the case of CAPE and, as a consequence, the global kinetic occurs under mixed control.

Table 1. Variation of oxidation potentials $v s$. the logarithm of the scan rate

\begin{tabular}{lc}
\hline Compound & $\partial \mathrm{Ep} / \partial \log v$ \\
\hline C & 38 \\
CA & 31 \\
DHCA & 39 \\
CAPE & 42 \\
G & 40 \\
FA & 30 \\
\hline
\end{tabular}

On the other hand, $\partial \mathrm{E}_{\mathrm{p}} / \partial \log v$ was analyzed for $\mathrm{C}$, DHCA and G (Table 1), in order to know the effect that the conjugation between the aromatic ring and the double bond exerts on the global kinetic oxidation mechanisms of CA and FA systems. The variation of $\partial \mathrm{E}_{\mathrm{p}} / \partial \log v$ was 38,39 ,

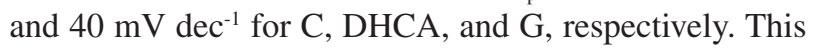
observation suggests that the oxidation mechanism for these compounds proceeds under mixed kinetic control. ${ }^{33}$

In addition, we found that the difference between the oxidation wave I and the reduction wave II for the conjugated systems CA, CAPE, and FA is smaller (326, 355 , and $447 \mathrm{mV}$, respectively) than in the case of the nonconjugated compounds C, DHCA, and G (530, 552, and $677 \mathrm{mV}$, respectively), since there is a higher stabilization of the radical cations coming from the oxidation of the catechol and guiacol moieties due to the presence of the conjugated double bond (Scheme 2).

On the other hand, Astudillo et al. ${ }^{32}$ reported that hydrogen bonding acceptor solvents play an important role on the anodic oxidation of hydroquinone. They proposed that DMSO interacts with hydroquinone through hydrogen bonding associations, causing the shift of the oxidation peaks toward less positive potentials. Taking into account the structural similarity between hydroquinone and the catechol moiety in C, CA, DHCA, and CAPE, we also analyzed the electrochemical behavior of these compounds in DMSO (Figure 3).

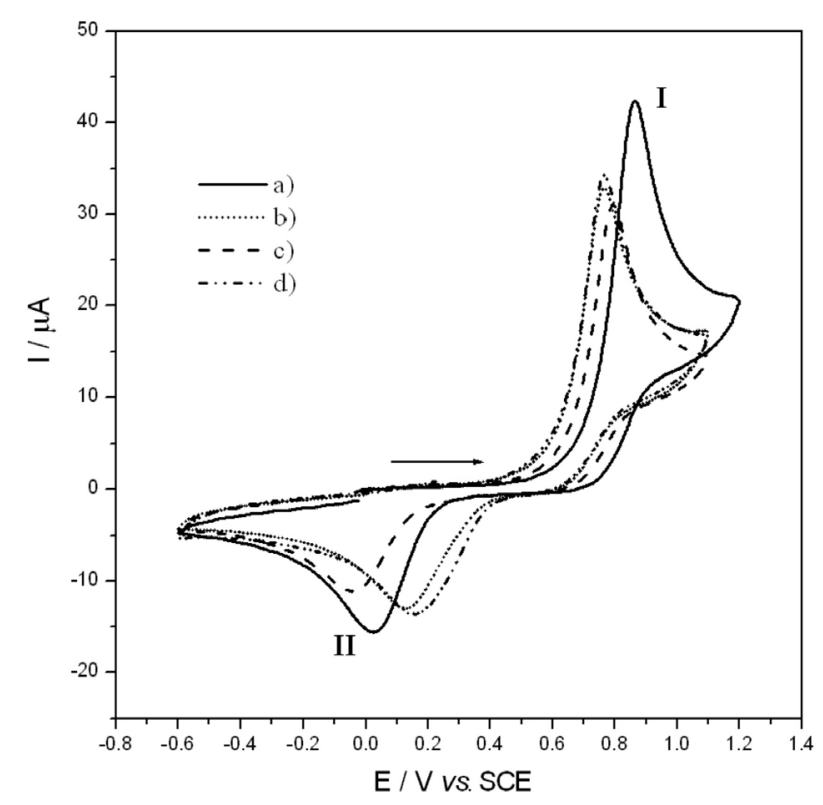

Figure 3. Cyclic voltammetry in DMSO $+0.2 \mathrm{~mol} \mathrm{~L}^{-1} n-\mathrm{Bu}_{4} \mathrm{NPF}_{6}$, on glassy carbon electrode $(3 \mathrm{~mm} \phi)$ at $2 \mathrm{mmol} \mathrm{L}^{-1}$ and $0.1 \mathrm{~V} \mathrm{~s}^{-1}$ of a) $\mathrm{C}$, b) CA, c) DHCA and d) CAPE.

As in the case of hydroquinone, the peak potentials of $\mathrm{C}$, CA, DHCA, and CAPE presented a displacement of $>250 \mathrm{mV}$ towards less anodic potentials in DMSO, in comparison with the measurements obtained in AN (Table 2).

The behaviour suggests that under these conditions the interaction between the catechol moiety $\left(\mathrm{QH}_{2}\right.$, scheme 1) of the four compounds with DMSO decreases the dissociation energy of the $\mathrm{O}-\mathrm{H}$ bonds, making the proton

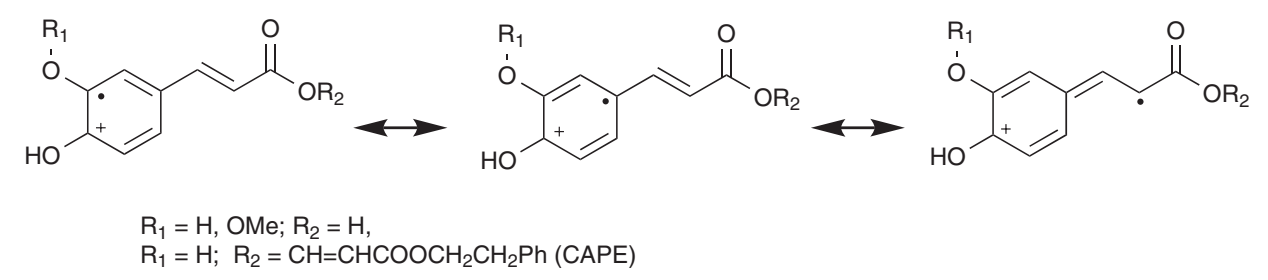


Table 2. Oxidation potentials of C, CA, DHCA, and CAPE in AN and DMSO $^{\mathrm{a}}$

\begin{tabular}{lcc}
\hline Compound & $\mathrm{E}_{\mathrm{p}}(\mathrm{AN}) / \mathrm{V} v s . \mathrm{SCE}$ & $\mathrm{E}_{\mathrm{p}}$ (DMSO) / V vs. SCE \\
\hline $\mathrm{C}$ & 1.11 & 0.86 \\
$\mathrm{CA}$ & 1.08 & 0.78 \\
DHCA & 1.07 & 0.79 \\
CAPE & 1.01 & 0.73 \\
\hline
\end{tabular}

${ }^{a}$ All oxidation potentials were obtained at $2 \mathrm{mmol} \mathrm{L}^{-1}$ and at $0.1 \mathrm{~V} \mathrm{~s}^{-1}$.

transfer reaction more favorable in the second step of the oxidation mechanism (reactions 1-3). This observation can be explained considering the fact that the proton affinity is higher in DMSO than in AN, and that the proton transfer in pure DMSO is carried out into a hydrogen bonding complex formed between the hydroxyl groups of catechol and the DMSO molecules. ${ }^{32,34}$

$$
\begin{aligned}
& \mathrm{QH}_{2}(\mathrm{DMSO}) \rightleftharpoons \mathrm{e}^{-} \\
& \mathrm{QH}_{2}^{\cdot+}(\mathrm{DMSO}) \rightleftharpoons \mathrm{QH}_{2}^{++}(\mathrm{DMSO}) \\
& \mathrm{QH}^{\cdot} \stackrel{-\mathrm{e}^{-}}{\rightleftharpoons} \mathrm{QH}^{\cdot}+\mathrm{DMSO}\left(\mathrm{H}^{+}\right)
\end{aligned}
$$

Additionally, the variation of $\mathrm{E}_{\mathrm{p}} v s . \log v$ for all the compounds (38.4-41.9 $\mathrm{mV} \mathrm{dec}^{-1}$ ) indicates a mixed kinetic control of steps 1 and 2 on the global reaction, which is not affected by the structural differences among the four compounds (C, CA, CAPE, and DHCA). This is a consequence of the competition between deprotonation and radical cation delocalization, where the most favored process is the first one.

Since hydrogen bonding acceptor solvents play an important role on the oxidation mechanisms of catechol and caffeic acid derivatives, we also carried out the cyclic voltammetry of G and FA in DMSO (Figure 4). A twoelectron chemically irreversible oxidation wave I was observed in both cases, however the voltammogram of FA shows additional oxidation and reduction waves, which

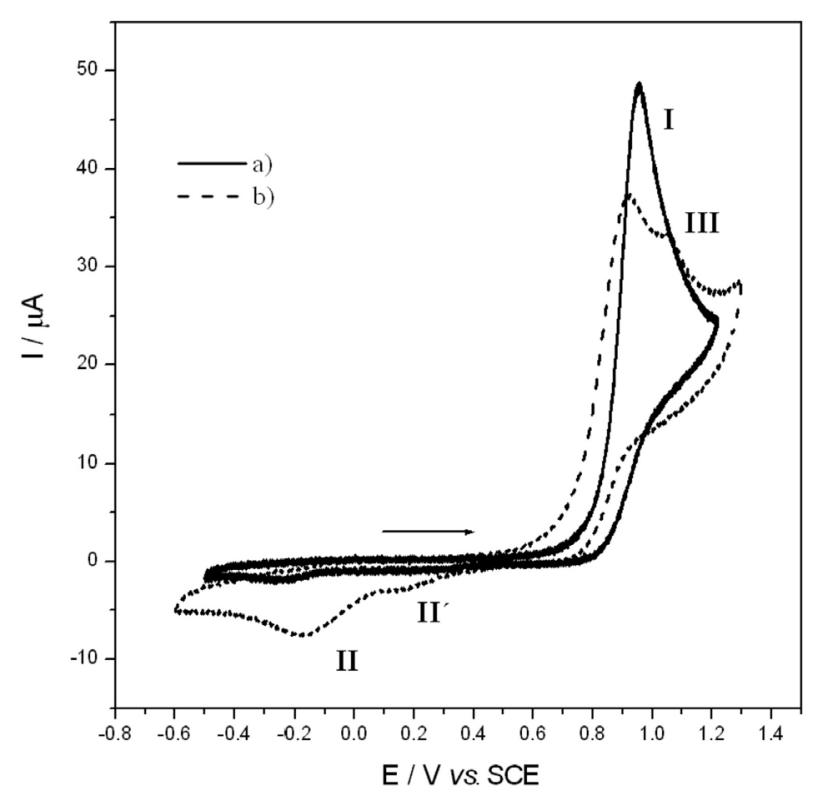

Figure 4. Cyclic voltammetry in DMSO $+0.2 \mathrm{~mol} \mathrm{~L}^{-1} n-\mathrm{Bu}_{4} \mathrm{NPF}_{6}$, on glassy carbon electrode $(3 \mathrm{~mm} \phi)$ at $2 \mathrm{mmol} \mathrm{L}^{-1}$ and $0.1 \mathrm{~V} \mathrm{~s}^{-1}$ of a) $\mathrm{G}$ and b) FA.

were labeled as III and II' $^{\prime}$ respectively in the Figure 4b. In addition, the reduction wave (II) intensity of $\mathrm{G}$ was smaller than the recorded for FA.

On the other hand, the analysis of the variation of $\mathrm{E}_{\mathrm{p}} v s . \log v$ on the wave I from the voltammogram of FA showed a slope of $23 \mathrm{mV} \mathrm{dec}{ }^{-1}$. This value is consistent with a radical-radical dimerization mechanism, since it has been previously reported that dimeric species can be formed during the chemical and electrochemical oxidation of neutral and dianionic hydroxycinnamic acid, respectively. ${ }^{28,33,35}$ Taking into account this result, it was proposed the dimerization mechanism of FA in DMSO as follow (Scheme 3).

Thus, the wave III observed in the cyclic voltammetry of FA corresponds to the oxidation of the guaiacol moieties present in the resulting dimer (Scheme 3). The absence of a second oxidation wave in the voltammogram of $\mathrm{G}$ and a slope of $36 \mathrm{mV} \mathrm{dec}{ }^{-1}$ calculated from the $\mathrm{E}_{\mathrm{p}} v s \cdot \log v$<smiles>COc1ccc(/C=C/C(=O)O)cc1OC</smiles><smiles>COc1cc(/C(=C/c2ccc(C=C(C(=O)O)C(=O)O)cc2OC)C(=O)O)ccc1O</smiles>

Scheme 3. 
variation from the corresponding wave I confirm this proposal. In addition, the reduction waves II observed in the voltammograms of both G and FA in DMSO (Figure 4), showed lower intensities respect to the data obtained in AN, which suggest that $o$-quinone is obtained in small quantities during their oxidation processes under these experimental conditions. However, the potential scan of the electrochemical responses of $\mathrm{G}$ and $\mathrm{FA}$ from -2 to $1.5 \mathrm{~V}$ (Figures 5 and 6 respectively), showed an additional

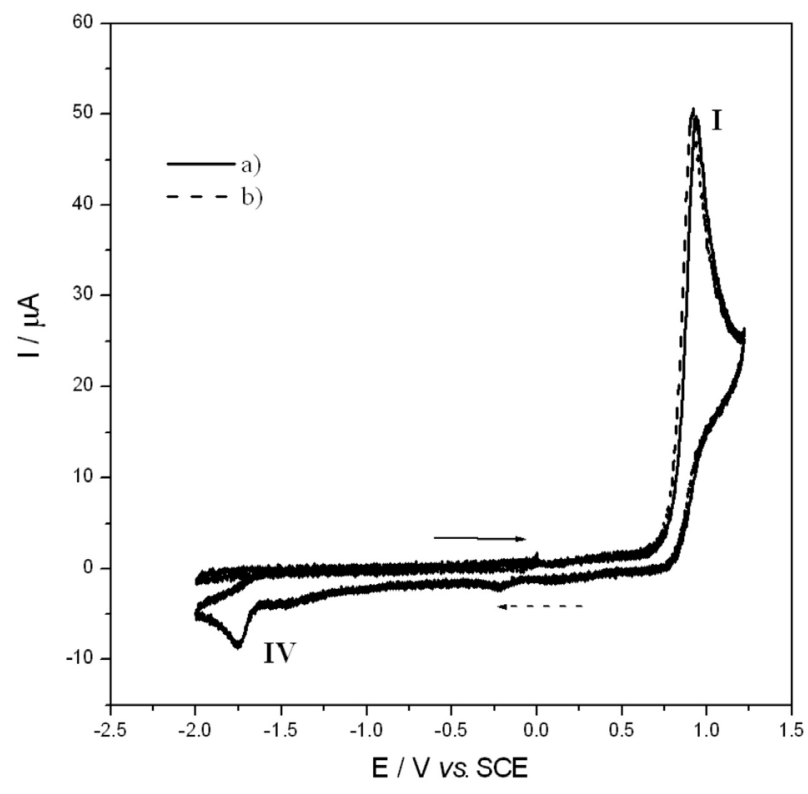

Figure 5. Cyclic voltammetry of $\mathrm{G}$ at $2 \mathrm{mmol} \mathrm{L}^{-1}$ in $\mathrm{DMSO}+0.2 \mathrm{~mol} \mathrm{~L}^{-1}$ $n-\mathrm{Bu}_{4} \mathrm{NPF}_{6}$, on glassy carbon electrode $(3 \mathrm{~mm} \phi)$. Scan from 1.5 to $-2.0 \mathrm{~V}$. a) anodic direction and b) cathodic direction.

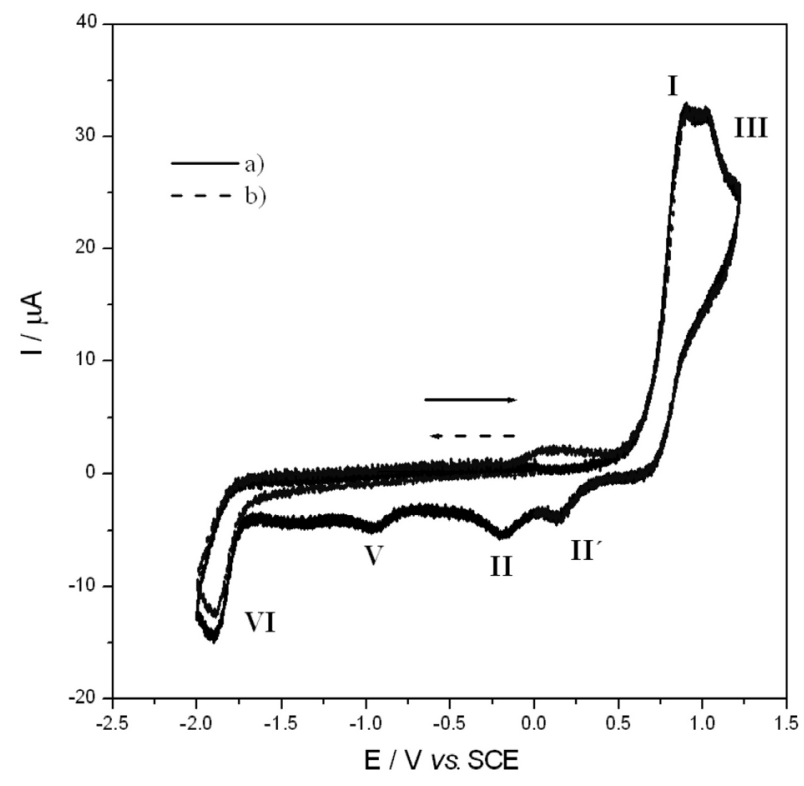

Figure 6. Cyclic voltammetry of FA $2 \mathrm{mmol} \mathrm{L}^{-1}$ in DMSO $+0.2 \mathrm{~mol} \mathrm{~L}^{-1}$ $n-\mathrm{Bu}_{4} \mathrm{NPF}_{6}$, on glassy carbon electrode $(3 \mathrm{~mm} \phi)$. Scan from 1.5 to $-2.0 \mathrm{~V}$. a) anodic direction and b) cathodic direction. reduction wave (IV) in $-1.75 \mathrm{~V}$ for $\mathrm{G}$ and two waves more (V and VI) for FA. It should be mentioned, however that the wave VI is also observed in the cyclic voltammetry of FA in AN.

From these results, it can be inferred that the products obtained during the oxidation processes of both compounds in DMSO, correspond to $o$-quinone or $p$-quinone derivatives, which are substituted with the methoxy group, and emerge from a nucleophilic attack between the water traces present in DMSO and a phenoxy cation generated in a second oxidation step (favored by the electron-releasing power of the methoxy group).

The presence of a methoxy group on the quinone type products is in agreement with the fact that the reduction waves found for $\mathrm{G}$ and FA (IV and V, respectively) are more negative than the wave II. ${ }^{36}$

Electrochemical behaviour of caffeic and ferulic acids amide derivatives in acetonitrile

The electrochemical behaviours of the caffeic (CABzA and CAPEA) and ferulic acid (FABzA and FAPEA) amide derivatives, in AN, are shown in Figures 7 and 8, respectively. In all the cases, it was observed the bielectronic oxidation peak I and its corresponding reduction peak II. Additionally, a small reduction wave (III) to less positive potential values is also observed for all the amides, and an oxidation wave $\mathrm{I}^{\prime}$ is recorded only in the voltammograms of FABzA and FAPEA.

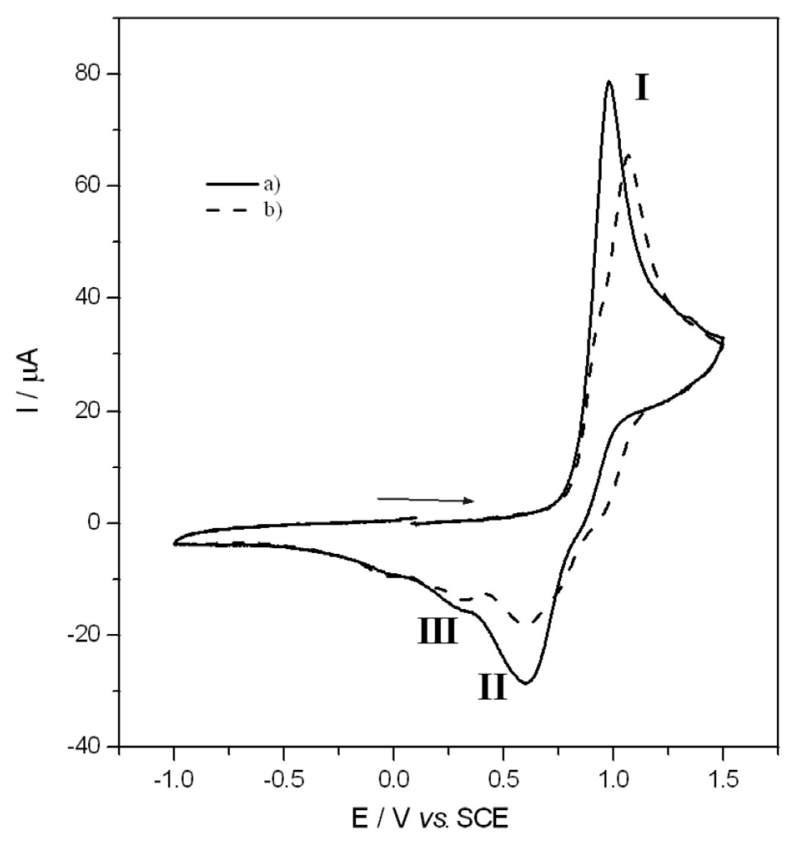

Figure 7. Cyclic voltammetry in acetonitrile $+0.2 \mathrm{~mol} \mathrm{~L}{ }^{-1} n-\mathrm{Bu}_{4} \mathrm{NPF}_{6}$, on glassy carbon electrode $(3 \mathrm{~mm} \phi)$ at $2 \mathrm{mmol} \mathrm{L}^{-1}$ and $0.1 \mathrm{~V} \mathrm{~s}^{-1}$ of a) CABzA and b) CAPEA. 


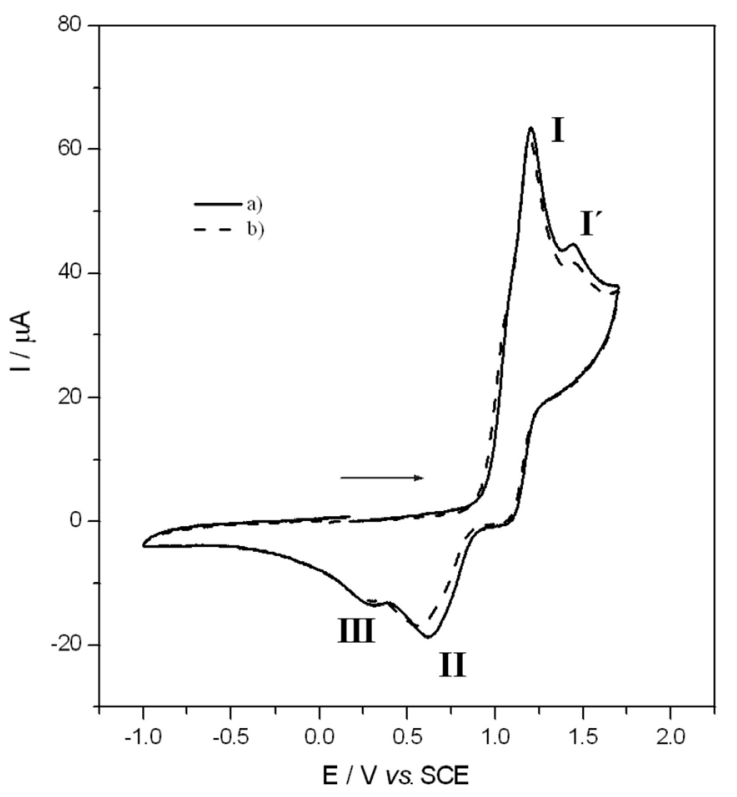

Figure 8. Cyclic voltammetry in acetonitrile $+0.2 \mathrm{~mol} \mathrm{~L}^{-1} n-\mathrm{Bu}_{4} \mathrm{NPF}_{6}$, on glassy carbon electrode $(3 \mathrm{~mm} \phi)$ at $2 \mathrm{mmol} \mathrm{L}^{-1}$ and $0.1 \mathrm{~V} \mathrm{~s}^{-1}$ of a) FABzA and b) FAPEA.

In the case of CABzA, when the scan rate is increased a new peak $\left(\mathrm{I}^{\prime}\right)$ appears toward more positive potentials respect to the wave I (Figure 9), which indicates that two oxidative processes must be occurring on this compound. On the other hand, the peak II and the post wave observed in both, CABzA and CAPEA, become a new broad reduction wave at high scan rates.

In addition, the corresponding anodic peak of FABzA and FAPEA decrease steadily with the number of cycles until they disappears completely (see supplementary information).

This behaviour could be related to the derivatization of the electrode surface phenomenon, since the voltammetric behaviour of FABzA is recovered if the electrode surface is polished. From these results, it is evident that the reactivity of the nitrogen atom must be considered also as a part of

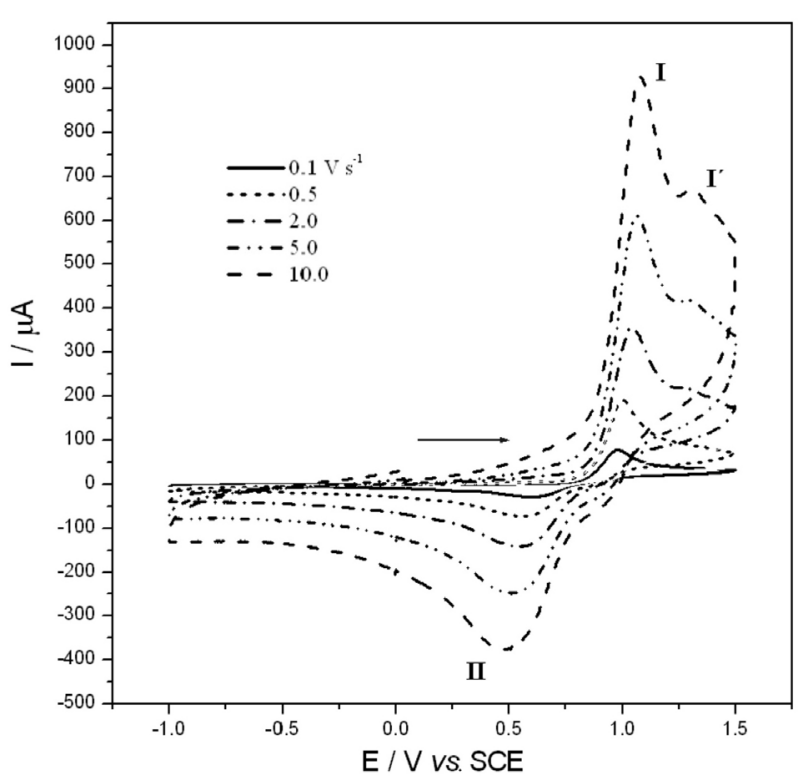

Figure 9. Cyclic voltammetry in DMSO $+0.2 \mathrm{~mol} \mathrm{~L}-1=-\mathrm{Bu}_{4} \mathrm{NPF}_{6}$, on glassy carbon electrode ( $3 \mathrm{~mm} \phi)$ of CABzA at $2 \mathrm{mmol} \mathrm{L}^{-1}$ and different scan rate.

the global oxidation mechanism of both compounds ${ }^{37,38}$ as follow (Scheme 4).

\section{Oxidation potentials vs radical scavenging activity}

The electrochemical parameters such as the redox potential, the number of electrons, and the electron transfer rate have been used to evaluate the oxidant capabilities of polyphenols. ${ }^{39-42}$ The redox potential could be a key factor that governs the antioxidant activity of this type of systems. Therefore, the oxidation potentials of polyphenols are often measured and compared to their antioxidant activities, including the radical scavenging activity. The DPPH assay has been extensively used to evaluate this property of the phenolic compounds, hydroxycinnamic acids and related systems. ${ }^{8-13,43,44}$ In order to see if the electrochemical

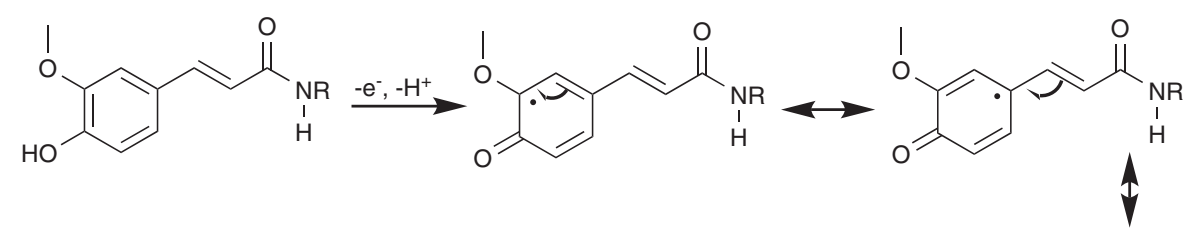<smiles>COC(=O)NCC(=O)NC=C1C=CC(=O)C(C(C)(C)C)=C1</smiles><smiles>COC1=CC(=CC2CCNC2=O)C=CC1=O</smiles>

GCE = Glassy Carbon Electrode $\mathrm{R}=\mathrm{CH}_{2} \mathrm{Ph}$, or $\mathrm{CH}_{2} \mathrm{CH}_{2} \mathrm{Ph}$ 
oxidation capability of all the compounds is linked in some way with their free radical scavenging activity, we carried out DPPH assays of the complete series.

The oxidation potential of the ten compounds reported in this work is shown in Table 3. As it can be observed, the highest values correspond to the guaiacol and ferulic systems, from 1.20 to $1.16 \mathrm{~V} v s$. SCE, whereas the catechol and caffeic acid derivatives exhibit oxidation potentials between 1.11 and $0.98 \mathrm{~V}$ vs. SCE.

Table 3. Oxidation potential of C, G, CA and FA derivatives and their corresponding inhibition percentage of 2,2'-diphenyl-1-picrylhidrazyl radical $(\mathrm{DPPH})$

\begin{tabular}{lcc}
\hline Compound & $\mathrm{E}_{\mathrm{p}} / \mathrm{V} v s . \mathrm{SCE}^{\mathrm{a}}$ & Inhibition / $(\%)( \pm \mathrm{SD}) \mathrm{DPPH}^{\mathrm{b}}$ \\
\hline $\mathrm{C}$ & 1.11 & $31.77 \pm 1.06$ \\
$\mathrm{CA}$ & 1.08 & $30.56 \pm 1.52$ \\
DHCA & 1.07 & $40.52 \pm 0.45$ \\
CAPE & 1.01 & $43.48 \pm 0.54$ \\
CABzA & 0.98 & $50.38 \pm 0.49$ \\
CAPEA & 1.07 & $36.86 \pm 1.49$ \\
G & 1.18 & $10.86 \pm 0.50$ \\
FA & 1.16 & $19.33 \pm 2.05$ \\
FABzA & 1.20 & $8.03 \pm 1.58$ \\
FAPEA & 1.19 & $10.81 \pm 0.47$
\end{tabular}

${ }^{\mathrm{a}}$ Oxidation potential of caffeic and ferulic acid derivatives were obtained at $2 \mathrm{mmol} \mathrm{L}^{-1}$ and at $0.1 \mathrm{~V} \mathrm{~s}^{-1}$ in acetonitrile. ${ }^{b}$ The values represent means \pm S.D. from three experiments and indicate the percentage of inhibition at $17 \mu \mathrm{mol} \mathrm{L}^{-1}$ of $\mathrm{C}, \mathrm{G}, \mathrm{CA}$ and FA derivatives.

In agreement with the electrochemical results, the catechol and caffeic systems showed a major inhibition percentage of the 2,2'-diphenyl-1-picrylhydrazyl radical (DPPH) between 30 to 50\%, whereas the guaiacol and ferulic acid derivatives showed a lower inhibition percentage between 10 and 20\% (Table 3). In addition, the lower oxidation potentials values of the series corresponded to caffeic acid phenethyl ester (CAPE) and one of the caffeic acid amides (CABzA) (1.01 and $0.98 \mathrm{~V}$, respectively). Both compounds exhibited also the higher scavenging radical activity (43.48 and $50.38 \%$ of inihibition respectively). A linear regression of the $\mathrm{E}_{\mathrm{p}}$ for the ten compounds against their inhibition percentage of a 2,2'-diphenyl-1-picrylhydrazyl radical (DPPH) showed a good agreement between the two sets of data (correlation coefficient of 0.978).

\section{Conclusions}

The electrochemical oxidation of the compounds studied in this work, catechol (C), guaiacol (G), caffeic acid (CA), dihydrocaffeic acid (DHCA), ferulic acid (FA), and caffeic acid phenethyl ester (CAPE), in acetonitrile follows an ECE mechanism. The analyses of the oxidation peak variation with the scan rate of the six compounds, demonstrated that in the case of CA and FA, the initial electron and proton transfer reactions are consecutive and they occur under kinetic control of the deprotonation chemical reaction, since the conjugation of the aromatic ring with the double bond exerts a major stabilization of the radical cation $\mathrm{QH}_{2}{ }^{++}$generated from the two compounds. In contrast, the oxidations of C, DHCA, G, and CAPE occur under kinetic mixed control. In addition, the substitution of the acidic proton of the caffeic acid by the phenethyl group in the case of CAPE, induces an increase in the rate of the chemical deprotonation.

On the other hand, the formation of hydrogen bond association complexes between DMSO and the catechol moiety of caffeic acid derivatives induce a displacement of the oxidation peaks toward less anodic values respect to the oxidation potentials obtained in AN. In addition, several methoxy quinone type compounds must be generated during the oxidation of $\mathrm{G}$ and FA. In the case of anodic oxidation of $F A$, the analysis of variation of $\mathrm{E}_{\mathrm{p}} v s$. scan rate revealed the establishment of a radical-radical dimerization mechanism in DMSO.

The voltammograms of the four amides analyzed here showed additional waves in AN, respect to the rest of the series. Adsorption processes were even observed during the oxidation of FABzA and FAPEA, which suggests that in addition to the catechol and guaiacol moieties, the nitrogen atom plays also an important role in the global oxidation mechanism of this type of compounds.

Finally, the analysis of the oxidation potential of the ten compounds in AN demostrated that catechol and caffeic acid derivatives have a major oxidation capacity respect to the guaiacol and ferulic analogues. This is in agreement with the radical scavenging activity evaluated through a DPPH assay. The results showed that CAPE and CABzA exhibited the lower oxidation potentials, as well as the highest reactivity with 2,2'-diphenyl-1-picrylhydrazyl radical. These results corroborate the observation made by other authors, since the reducing power of an antioxidant could be a key factor that governs its antioxidant activity. ${ }^{39,42}$

\section{Supplementary Information}

Supplementary data are available free of charge at http://jbcs.sbq.org.br, as PDF file.

\section{Acknowledgments}

M. S. R thanks CONACyT-México for the financial support given to this work through project 52064. J. H. thanks CONACyT México and COVECyT México for 
FOMIX VER-2009-C03-127523. We are very grateful to Dr. Myrna H. Matus and Dr. Gabriel Merino for their comments. E. Martinez-Benavidez thanks also to CONACyT-México for a Master scholarship.

\section{References}

1. Herrmann, K.; Crit. Rev. Food Sci. Nutr. 1989, 28, 315.

2. Burdock, G. A.; Food Chem. Toxicol. 1998, 36, 347.

3. Velazquez, C.; Navarro, M.; Acosta, A.; Angulo, A.; Domínguez, Z.; Robles, R.; Robles R.; Lugo, E.; Goycoolea, F. M.; Velázquez, E. F.; Astiazaran, H.; Hernández, J.; J. Appl. Microbiol. 2007, 103,1747.

4. Beck, J. J.; Kim, J. H.; Campbell, B. C.; Chou, S-C.; J. Nat. Prod. 2007, 70, 779.

5. Burke, T. R. Jr.; Fesen, M.; Mazumder, A.; Yung, J.; Wang, J.; Carothers, A. M.; Grunberger D.; Driscoll, J.; Pommier, Y.; Kohn, K.; J. Med. Chem. 1995, 38, 4171.

6. Hernandez, J.; Goycoolea, F. M.; Quintero, J.; Acosta, A.; Castañeda, M.; Domínguez, Z.; Robles, R.; Vázquez-Moreno, L.; Velázquez, E. F.; Astiazaran, H.; Lugo, E.; Velázquez, C.; Planta Med. 2007, 73,1469.

7. Nagaoka, T.; Banskota, A. H.; Tezuka, Y.; Saiki, I.; Kadota, S.; Bioorg. Med. Chem. 2002, 10, 3351.

8. Chen, J. H.; Ho, J. C-T.; J. Agric. Food Chem. 1997, 45, 2374.

9. Rajan, P.; Vedernikova, I.; Cos, P.; Berghe, V. D.; Ausgustyns, K.; Haemers, A.; Bioorg. Med. Chem. Lett. 2001, 11, 215.

10. Son, S.; Lewis, B. A.; J. Agric. Food Chem. 2002, 50, 468.

11. Kikuzaki, H.; Hisamoto, M.; Hirose, K.; Akiyama, K.; Taniguchi, H.; J. Agric. Food Chem. 2002, 50, 2161.

12. Nenadis, N.; Zhang, H.-Y.; Tsimidou, M. Z.; J. Agric. Food Chem. 2003, 51, 1874.

13. Ordoudi, S. A.; Tsimidou, M. Z.; Vafiadis, A. P.; Bakalbassis, E. G.; J. Agric. Food Chem. 2006, 54, 5763.

14. Borreli, F.; Maffia, P.; Pinto, L.; Ianaro, A.; Russo, A.; Capasso, F.; Ialenti, A.; Fitoterapia 2002, 73, S53.

15. Chen, J-H; Shao, Y.; Huang, M-T.; Chin, C-K.; Ho, C-T.; Cancer Lett. 1996, 108, 211.

16. Lee, Y-J.;.Liao, P-H; Chen, W-K.; Yang, C-C.; Cancer Lett. 2000, 153, 51 .

17. Michaluart, P.; Masferrer, J. L.; Carothers, A. M.; Subbaramaiar, K.; Zweifel, B. S.; Koboldt, C.; Mestre, J. R.; Grunberger, D.; Sacks, P. G.; Tanabe, T.; Dannenberg, A. J.; Cancer Res. 1999, 59, 2347.

18. Sud`ina, G. F.; Mirzoeva, O. K.; Pushkareva, M.A.; Korshunova, G. A.; Sumbatyan, N. V.; Varfolomeev, S. D.; FEBS J. 1993, 329, 21.

19. Nomura, M.; Kaji, A.; Ma, W.; Miyamoto, K.; Dong, Z.; Mol. Carcinog. 2001, 31, 83.

20. Chiao, C.; Carothers, A. M.; Grunberger, D.; Solomon, G.; Preston, G. A.; Barrett, J. C.; Cancer Res. 1995, 55, 3576.
21. Giacomelli, C.; Ckless, K.; Galato, D.; Miranda, F. S.; Spinelli, A.; J. Braz. Chem. Soc. 2002, 13, 332.

22. Hotta, H.; Ueda, M.; Nagano, S.; Tsujino, Y.; Koyama, J.; Osakai, T.; Anal. Biochem. 2002, 303, 66.

23. Trabelsi, A. K.; Tahar, N. B.; Abdelhedi, R.; Electrochim. Acta 2004, 49, 1647.

24. Arakawa, R.; Yamaguchi, M.; Hotta, H.; Osakai, T.; Kimoto, T.; J. Am. Soc. Mass Spectrom. 2004, 15, 1228.

25. Hapiot, P.; Neudeck, A.; Pinson, J.; Fulcrand, H.; Neta, P.; Rolando, C.; J. Electroanal. Chem. 1996, 405, 169.

26. Rapta, P.; Vladimir, M.; Stasko, A.; Vrábel, I.; Free Radical Biol. Med. 1995, 18, 901.

27. Grunberger, D.; Banerjee, R.; Eisinger, K.; Oltz, E. M.; Efros, L.; Caldwell, M.; Estevez, V.; Nakanishi, K.; Experientia 1988, 44, 230.

28. Petrucci, R.; Astolfi, P.; Greci, L.; Firuzi, O.; Saso, L.; Marrosu, G.; Electrochim. Acta 2007, 52, 2461.

29. Parker, V. D.; Chem. Commun. 1969, 716.

30. Parker, V. D.; Eberson, L.; Chem. Commun. 1970, 1289.

31. Parker, V. D.; Electrochim. Acta 1973, 18, 519.

32. Astudillo D. P.; Tiburcio, J.; González, F. J.; J. Electroanal. Chem. 2007, 604, 57.

33. L. Nadjo, L.; Savéant, J. M.; J. Electroanal. Chem. 1973, 48, 113.

34. Foti, M. C.; Ross, L.; Barclay, C.; Ingold, K. U.; J. Am. Chem. Soc. 2002, 124, 12881.

35. Savéant, J. M.; Elements of Molecular and Biomolecular Electrochemistry: An Electrochemical Approach to Electron Transfer Chemistry, Wiley-Interscience: New Jersey, 2006.

36. Bautista-Martínez, J. A.; González, I.; Aguilar-Martínez, M.; J. Electroanal. Chem. 2004, 573, 289.

37. Weinberg, N. L.; Weinberg, H. R.; Chem. Rev. 1968, 68, 449.

38. Garrido, E.M.; Lima, J. L. F. C.; Delerue-Matos, C.; Borges, F.; Silva, Oliveira A. M. S.; Brett, A. M.; Anal. Chim. Acta 2001, 434, 35.

39. Born, M.; Carrupt, P-A; Zini, R.; Brée, F.; Tillement, J-P.; Hostettmann, K.; Testa, B.; Helv. Chim. Acta 1996, 79, 1147.

40. Peyrat-Maillard, M. N.; Bonnely, S.; Berset, C.; Talanta 2000, 51, 709.

41. Yang, B.; Kotani, K.; Arai, K.; Kusu, F.; Anal. Sci. 2001, 17, 599.

42. Hotta, H.; Nagano, S.; Ueda, M.; Tsujino, Y.; Koyama, J.; Osakai, T.; Biochim. Biophys. Acta 2002, 1572, 123.

43. Huang, D.; Ou, B.; Priori, R. L; J. Agric. Food Chem. 2005, 53, 1841.

44. Foti, M. C.; Daquino, C.; Geraci; C., J. Org. Chem. 2004, 69, 2309.

Submitted: May 7, 2010

Published online: December 21, 2010 


\section{Electrochemical Oxidation of Caffeic and Ferulic Acid Derivatives in Aprotic Medium}

\section{Magali Salas-Reyes,,$* a$ Javier Hernández, ${ }^{a}$ Zaira Domínguez, ${ }^{a}$ Felipe J. González, ${ }^{b}$ \\ Pablo D. Astudillo, ${ }^{b}$ Rosa Elena Navarro, ${ }^{c}$ Evelin Martínez-Benavidez, ${ }^{d, a}$ \\ Carlos Velázquez-Contreras ${ }^{e}$ and Samuel Cruz-Sánchez ${ }^{a}$}

${ }^{a}$ Unidad de Servicios de Apoyo en Resolución Analítica, Universidad Veracruzana, Apdo. Postal 575, Xalapa, Ver., México

${ }^{b}$ Departamento de Química del Centro de Investigación y Estudios Avanzados, Av. Instituto

Politécnico Nacional 2508, 07360, Apdo. Postal 14-740, México, D. F., México

'Departamento de Investigación en Polímeros y Materiales, Hermosillo, Son., México

${ }^{d}$ Instituto de Ciencias Básicas, Universidad Veracruzana, Apdo. Postal 525, Xalapa, Ver., México

${ }^{e}$ Departamento de Ciencias Químico Biológicas, Universidad de Sonora, 83000, Hermosillo, Son., México

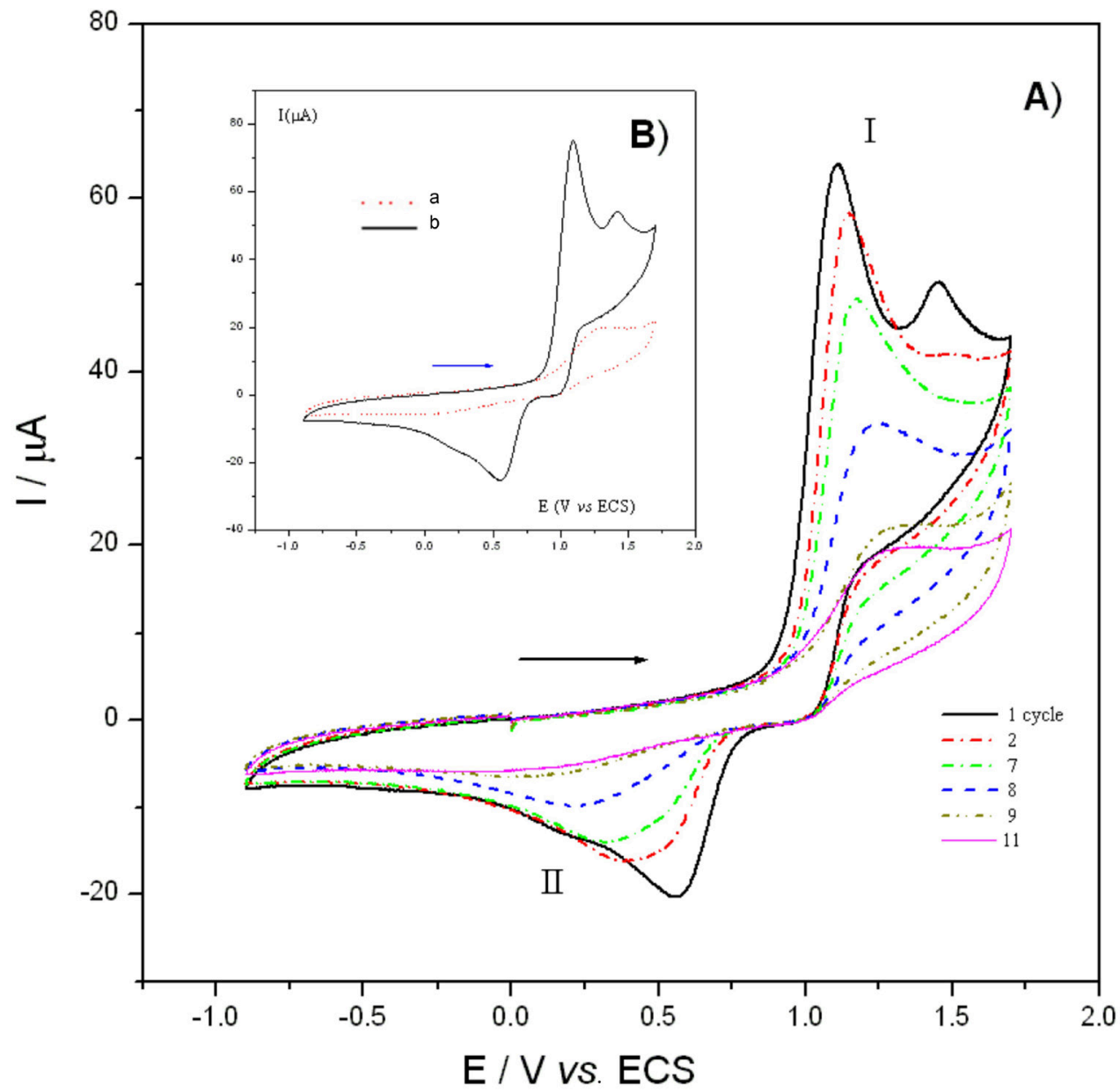

Figure S1. Cyclic voltammetries of FABzA in acetonitrile $+0.2 \mathrm{~mol} \mathrm{~L}^{-1} \mathrm{n}-\mathrm{Bu}_{4} \mathrm{NPF}_{6}$, on glassy carbon electrode $(3 \mathrm{~mm} \phi)$ at $0.1 \mathrm{~V} \mathrm{~s}^{-1}$ and $2 \mathrm{mmol} \mathrm{L}^{-1}$. A) During eleven continuous cycles and B) (a) Cyclic voltammetry of FABzA on $11^{\text {th }}$ cycle; (b) after polishing electrode surface. 